\title{
CIDADANIA, DEMOCRACIA E SABER ESCOLAR NA LEGISLAÇÃO DO ENSINO MÉDIO NO BRASIL
}

\section{CITIZENSHIP, DEMOCRACY AND SCHOOL KNOWLEDGE IN \\ HIGH SCHOOL LEGISLATION IN BRAZIL}

\author{
Mauro Cezar Coelho ${ }^{1}$ \\ Rafael da Silva Saldanha ${ }^{2}$
}

\begin{abstract}
RESUMO: Este artigo analisa as implicações epistemológicas das categorias cidadania e democracia, presentes no conjunto de documentos que compõem a Legislação educacional emanada do Governo Federal para o Ensino Médio. Constituíram o corpus documental do artigo desde a Constituição Federal, publicada em 1988, até a mais recente Reforma do Ensino Médio, por meio da Lei 13.415/2017, incluindo-se várias diretrizes, pareceres, orientações e parâmetros curriculares publicados nesse período. A análise se baseou na elucidação dos sentidos assumidos por essas categorias nos documentos considerados, em seu contexto de produção e na sistematização do conceito de saber escolar, feita por Ana Maria Monteiro. A análise revelou que as afirmações relacionadas às categorias cidadania e democracia informam um conjunto de valores específicos que, forjados pela sociedade brasileira, legitimam formalmente a dimensão educativa-ideológica dos saberes escolares, redimensionando o espaço ocupado e reconfigurando o papel desempenhado pelos saberes acadêmicos específicos que servem de referência às disciplinas escolares.
\end{abstract}

Palavras-chave: Saber escolar. Legislação educacional. Cidadania e democracia. Ensino médio.

ABSTRACT: This article analyzes the epistemological implications of the categories citizenship and democracy, featured in the set of documents that compose the educational legislation issued by the Federal Government for High School. This article's documentary corpus included since the Federal Constitution, published in 1988, until the most recent High School Reform, through Law 13,415 / 2017, including several guidelines, opinions, orientations and curricular parameters published during this period. The analysis was based on the elucidation of the meanings assumed by these categories in the documents considered, in their production context and in the systematization of the concept of school knowledge,

1 Doutorado em História Social pela Universidade de São Paulo (2006). Professor Adjunto da Universidade Federal do Pará. E-mail: mauroccoelho@yahoo.com.br.

2 Doutorando pelo Programa de Pós-graduação em História da Universidade Federal do Pará. Professor da Rede Pública de Ensino (SEDUC/SEMEC). E-mail: rafael_saldanha@hotmail.com. 
made by Ana Maria Monteiro. The analysis revealed that the statements related to the categories citizenship and democracy inform a set of specific values that, forged by Brazilian society, formally legitimize the educational-ideological dimension of school knowledge, resizing the space occupied and reconfiguring the role played by the specific academic knowledge that function as a reference for school subjects.

Keywords: school knowledge; educational legislation; citizenship and democracy; High School.

Recentemente, temos assistido a uma emergência de políticas que buscam reformar o sistema de ensino, em seus diversos níveis. Dentre elas, as que mais têm suscitado discussão são aquelas relacionadas à Educação Básica. A introdução de uma base curricular comum, ainda que prevista pela Legislação desde a Constituição de 1988, fez emergir um debate acalorado acerca do que deve ser ensinado. A denominada Reforma do Ensino Médio tem provocado discussões que abordam desde a sua legitimidade, diante do modo como foi conduzida, até a estrutura curricular encaminhada. Discutir tais políticas é, portanto, pauta urgente.

Muitas das questões trazidas pelos instrumentos que implementam estas reformas estão previstas no escopo da Legislação Nacional, desde 1988. Isto, evidentemente, não torna melhores as mudanças propostas, mas indica que elas, em alguma medida, estão reportadas a discussões que atravessam os últimos trinta anos de nossa trajetória histórica e pautaram (ou, pelo menos, deveriam tê-lo feito) as reflexões de todos aqueles diretamente envolvidos com a Educação Básica - professores dos ensinos Fundamental e Médio e professores de cursos de licenciatura.

A discussão que oferecemos busca elucidar alguns aspectos das propostas de reformulação do Ensino Médio, indicando sua remissão à Legislação construída desde a promulgação da Carta Magna. Não é nossa intenção dimensionar as tensões sociais que resultaram no aparato legislativo que disciplina o saber escolar ou os desdobramentos de tais conflitos nas políticas educacionais. O que pretendemos é evidenciar o quanto a legislação educacional tem refletido certas demandas da sociedade e dos sistemas de ensino e, por conseguinte, restringido ou disciplinado a 
produção dos saberes escolares. Estes últimos conformam, portanto, o foco de nossa discussão, de modo que não realizaremos uma análise da construção do corpo legislativo (o que, de resto, demandaria um estudo específico). Antes, é nossa intenção indicar como os saberes escolares estão remetidos a dimensões outras, demandadas e definidas pela sociedade, e não apenas aos saberes acadêmicos específicos que servem de referência às disciplinas que compõem o currículo e, por conseguinte, à formação no ensino médio.

\section{O escopo da discussão}

Os indicadores educacionais para o ensino médio recorrentemente têm apresentado perspectivas pouco animadoras em relação ao enfrentamento das principais problemáticas que atingem essa etapa da educação básica (CASTRO; TORRES; FRANÇA, 2013, p. 5). A evasão, o fracasso escolar e o baixo rendimento dos alunos em avaliações de larga escala continuam surpreendendo negativamente os responsáveis pela condução da política educacional brasileira (CÂMARA DOS DEPUTADOS, 2013, p. 7). São reflexos da carência de condições educativas adequadas à maioria das crianças e jovens, algo visto não apenas no Brasil, mas também nos demais países da América Latina (FRIGOTTO; CIAVATTA, 2011, p. 620).

O caso brasileiro, contudo, destaca-se pelo fato de a Educação Básica constituir um direito público subjetivo estabelecido desde a Constituição de 1988 (BRASIL, 2017a, Art. 208, Parágrafo 10). A educação é, ao mesmo tempo, uma prerrogativa do cidadão e uma obrigação do Estado. Nos termos em que esta obrigação é definida, entretanto, configura-se um ideal que contrasta com a realidade educacional. A manutenção de um currículo que continua vivo em suas manifestações mais atrasadas é um dos fatores que se pode apontar para essa incompatibilidade (FINI, 2014, p. 365). Trata-se de algo que, inclusive, coincide com a representação que muitos 
professores e alunos possuem a respeito do que é ensinado nas escolas. Para esses sujeitos, os assuntos trabalhados em sala de aula não possuem atratividade e significado, são conteúdos abstratos e distantes do universo de significação das crianças e adolescentes e sem articulação com a experiência cotidiana (CAIMI, 2006, p. 18).

Uma das explicações para essa situação consiste na influência ainda vivaz do paradigma da racionalidade técnica (GATTI JUNIOR, 2010, p.59; SOUZA NETO, 2019, p. 400), em voga nos anos 1970, sobre as práticas pedagógicas no Brasil. Voltado para a busca da eficácia através do controle científico do processo educacional escolar, esse paradigma via no professor um profissional habilitado para adequar o conhecimento científico em saber a ser aprendido pelos alunos (MONTEIRO, 2007, p. 71). Segundo esse paradigma, os saberes não eram alvo de questionamentos ou reflexão, mas apenas de simplificação e memorização (CHERVEL, 1990, p. 200). Essa perspectiva racionalista, contudo, tem sido solapada por pesquisas que ressaltam o reducionismo e os equívocos operados por essa concepção educacional, especialmente no que diz respeito à vinculação estreita e reducionista entre o saber escolar e o conhecimento científico (CHERVEL, 1990, p. 180-183; KNAUSS, 2005, p. 290; MONTEIRO, 2007, p. 72).

Discussões e reflexões no campo da epistemologia, por exemplo, têm demonstrado a relatividade do conhecimento científico, descartando a visão de que a ciência produz a única forma de conhecimento válido e reconhecendo a diversidade de formas de conhecimento com diferentes racionalidades e formas de validação (MOREIRA, 1997, p. 23; MONTEIRO, 2007, p. 72). O próprio conhecimento científico, convém ressaltar, não é homogêneo na medida em que comporta diferentes metodologias, modelos explicativos e racionalidades (KNAUSS, 2005, p. 290). Um dos avanços desenvolvidos na esteira destas discussões é o conceito renovado de saber escolar, o qual designa um tipo de saber com configuração cognitiva própria e original da cultura escolar (MONTEIRO, 2003, p. 13), que envolve interlocução com o saber acadêmico, mas não se restringe a ele posto que aciona e articula também outros saberes e demandas que circulam no contexto social e cultural de referência de professores e alunos (MONTEIRO, 
2003, p. 11). O conceito de saber escolar, nestes termos, evidencia a existência de uma complexa miscelânea epistemológica que se contrapõe ao entendimento do mesmo como simplificação ou adaptação do saber acadêmico.

Uma das características dessa representação de saber escolar é apoiar-se na heterogeneidade e diversidade do conhecimento científico. Este é, inclusive, um elemento distintivo do saber escolar em relação ao seu congênere acadêmico: o saber escolar se permite fazer o que no campo do saber acadêmico seria inconcebível, a saber, utilizar-se de diferentes formas de pensar, recorrendo ao que convém no processo de ensino e aprendizagem. Isso não significa, entretanto, como demonstraremos, que os saberes escolares sejam fruto de voluntarismos, diletantes ou que inexistam parâmetros e referências pré-estabelecidas à sua construção.

O conceito de saber escolar, inclusive, desempenha um papel central para o entendimento da epistemologia desses saberes. Além do esclarecimento sobre a variedade de saberes, perspectivas e demandas que são sintetizadas em seu interior, o conceito também evidencia a existência de uma função educativa, a qual demanda que os saberes selecionados sejam tornados transmissíveis e assimiláveis (MONTEIRO, 2003, p. 13). A conformação do saber escolar congrega um processo de reorganização e reestruturação que the fornece as configurações cognitivas típicas do ambiente escolar (MONTEIRO, 2003, p. 13; MONTEIRO, 2007, p. 73). Neste processo de escolhas e articulação de saberes, demandas e perspectivas teóricas e pedagógicas, verifica-se também um trabalho nem sempre consciente e intencional de assunção de valores e disciplinamento de atitudes (MONTEIRO, 2007, p. 82). Esse entendimento, é importante que se diga, vai de encontro ao discurso conservador segundo o qual às disciplinas escolares deve ser relegado apenas a aprendizagem dos conhecimentos científicos tendo em vista a consecução de uma suposta neutralidade ideológica. 
Os saberes escolares, pelo contrário, sempre expressam uma dada configuração ideológica porque incluem, ainda que implicitamente, por meio de silenciamentos, trivialização de assuntos e estereotipagens (SANTOMÉ, 1995, p. 172-177), aprendizagens sobre nacionalidade, gênero, raça ou etnia (BLOOM, 2013, p. 67; SILVA, 1999, p. 79).

O conceito de saber escolar, em suma, torna explícitas as bases sobre as quais o mesmo é erigido, constituindo uma espécie de topografia da epistemologia desenvolvida no interior das disciplinas. Trata-se de um conceito assaz profícuo, em primeiro lugar, porque legitima a autonomia do saber escolar em relação ao saber acadêmico ao permitir a exploração de diferentes saberes e modelos científicos, não se comprometendo de maneira exclusivista com nenhuma lógica explicativa em particular comprometimento este que é próprio do espaço acadêmico. Em segundo lugar, porque redefine a prática epistemológica em sala de aula, indo além da caricatura, da mera memorização de fórmulas ou da caça a fatos e acontecimentos (KNAUSS, 2005, p. 293), marcas do saber escolar constituído em função do paradigma da racionalidade técnica.

E mais: a utilização do conceito de saber escolar como aporte teórico neste trabalho permitiu a identificação fina, na documentação eleita, das determinações que disciplinam a conformação dos saberes escolares, especificamente as afirmações que acionam as categorias cidadania e democracia. Partimos, em nossa análise, dos documentos que compõem a Legislação educacional porque os consideramos, assim como Nunes, um dos dispositivos de conformação das práticas pedagógicas e curriculares (NUNES, 2007, p. 42). Os documentos legais veiculam um discurso específico sobre a conformação dos saberes escolares, que congrega uma série de parâmetros que vincula, de modo formal, as bases da epistemologia dos saberes escolares, especificamente, no caso das categorias analisadas neste artigo, os valores e atitudes desejáveis que constituíram os objetivos a serem alcançados e as possíveis maneiras como os diversos saberes poderão ser sintetizados no interior das disciplinas escolares. 
O conhecimento dessas vinculações, destaque-se, é uma lacuna nos estudos sobre a Legislação educacional, os quais têm ressaltado, invariavelmente, a influência nociva dos organismos internacionais em sua composição. Disto tem resultado uma compreensão superficial da norma jurídica, a qual também está presente no cotidiano das escolas, nas falas de professores e técnicos pedagógicos. A existência dessa compreensão reducionista do papel da Legislação se evidencia, por exemplo, quando os professores manifestam sua contrariedade em relação ao que Ihes é prescrito legalmente, seja criticando abertamente a Legislação, seja negligenciando-a, fingindo cumprir suas exigências quando, efetivamente, estão a fazer o que consideram correto (CERRI, 2004, p. 218).

Esse modo de lidar com o sistema legal (CERRI, 2004, p. 230) é indicativo de uma compreensão equivocada a respeito dos limites que efetivamente Ihes são impostos pelas prescrições legais. A natureza altamente subjetiva da profissão docente, a qual decorre do trabalho vicário desempenhado pelos professores, e a composição discursiva das afirmações que informam os parâmetros legais de conformação dos saberes escolares, todavia, não são elementos mutuamente excludentes. As determinações presentes nos documentos que compõem a Legislação Educacional considerada, não estabelecem rotinas ou itinerários, mas princípios, valores e aberturas epistemológicas à construção dos saberes escolares. As balizas estabelecidas na Legislação não se assemelham a uma caixa padronizada que todo professor deverá abrir em sala de aula, um tipo de receituário que se deve seguir à risca. Pelo contrário. A composição do discurso legal sobre a conformação dos saberes escolares, embora congregue uma série de exigências, confere um alto grau de discricionariedade aos professores na produção destes saberes. 
Figura 1 - Ilustra a hierarquia jurídica da Legislação Educacional.

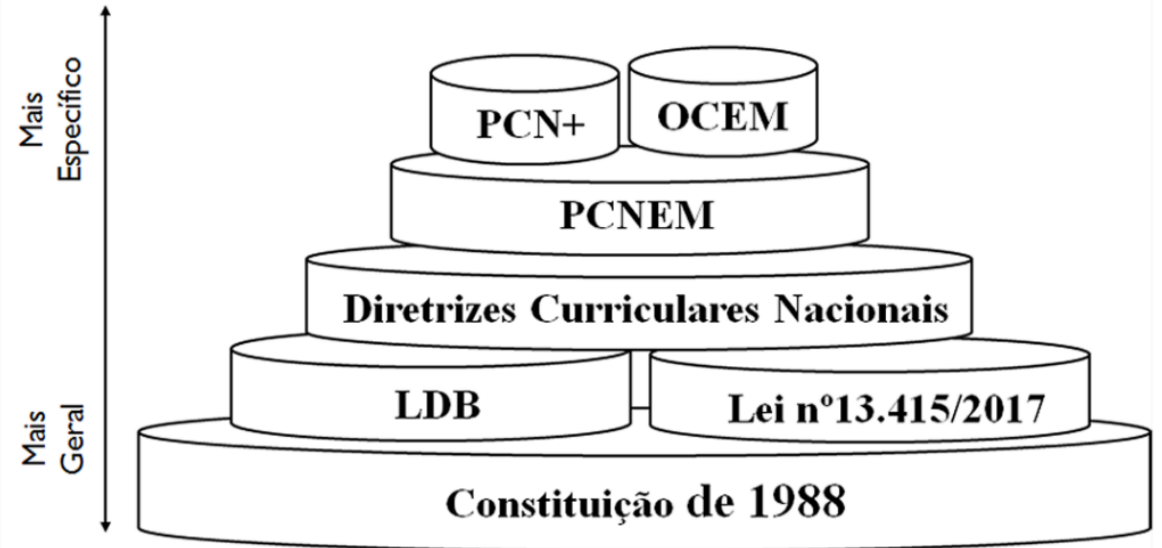

Fonte: Saldanha, 2017, p. 59.

A figura 1, acima, ilustra os documentos que compuseram a Legislação educacional analisada. Em seu ápice, estão as Orientações Educacionais Complementares aos Parâmetros Curriculares Nacionais (PCN+) (BRASIL, 2002a; BRASIL, 2002b; BRASIL, 2002c) e as Orientações Curriculares para o Ensino Médio (OCEM) (BRASIL, 2006a; BRASIL, 2006b; BRASIL, 2006c). São documentos que estabelecem diálogo imediato com os Parâmetros Curriculares Nacionais para o Ensino Médio (PCNEM) (BRASIL, 2000a; BRASIL, 2000b; BRASIL, 2000c; BRASIL, 2000d) e, por isso, estão posicionados sobre eles. Mais abaixo, com força de lei, encontram-se as Diretrizes Curriculares Nacionais (DCN) (BRASIL, 2004a; BRASIL, 2004b; BRASIL, 2010a; BRASIL, 2010b; BRASIL, 2011; BRASIL, 2012). Em seguida, vem a Lei de Diretrizes e Bases da Educação (LDB) (BRASIL, 2017b) e a Lei no 13.415/2017 (BRASIL, 2017c) que a altera. Na base de todos os documentos, encontra-se a Constituição de 1988 (BRASIL, 2017a). Como se vê na figura, têm-se um encadeamento jurídico que parte de definições mais gerais, na base, para definições mais específicas, no ápice.

Além do conceito de saber escolar, sistematizado por Ana Maria Monteiro, a análise se baseou na elucidação dos sentidos assumidos pelas categorias cidadania e democracia nos documentos elencados e em seu contexto de produção. Na seção a seguir, pode-se verificar como as ligações contextuais das afirmações destacadas da Legislação contribuem para o 
entendimento do discurso legal sobre a conformação dos saberes escolares. As conexões contextuais trazidas à tona nessa seção evidenciam as vinculações legais relativas tanto aos valores e atitudes assumidos quanto às suas implicações didáticas.

\section{O preparo para a cidadania e a democracia}

Do ponto de vista legal, a conformação dos saberes escolares no Brasil está vinculada à veiculação de certos valores ligados às categorias cidadania e democracia. Trata-se de uma demanda que, oriunda do papel específico atribuído à formação escolar desde a Constituição de 1988 (BRASIL, 2017a, Art. 205), incide diretamente sobre os objetivos e a construção dos saberes escolares. De acordo com a Constituição de 1988,

Art. 205. A educação, direito de todos e dever do Estado e da família, será promovida e incentivada, com a colaboração da sociedade. Visando ao pleno desenvolvimento da pessoa, seu preparo para o exercício da cidadania e sua qualificação para o trabalho. (BRASIL, 2017a, Art. 205)

A categoria cidadania atrelada ao processo educacional na Constituição, entretanto, haja vista sua longa trajetória de utilização na sociedade brasileira, não se constitui enquanto termo monossêmico, com significação e sentido unívocos. Cidadania é uma categoria que vem sendo acionada, de modo peculiar, desde a institucionalização da História Escolar e da constituição dos Estados-Nação no século XIX. Naquele período, ser cidadão significava ter orgulho de pertencer à nação, respeitá-la e dedicarse a servi-la (LAVILLE, 1999, p. 126). O fomento ao patriotismo por meio do conhecimento e do estabelecimento de vínculos com símbolos pátrios era aquele momento uma das principais marcas dos saberes escolares. Resquícios desse viés cívico-pedagógico caracterizado pela transmissão de saberes relacionados ao processo de construção da nacionalidade brasileira ainda podem ser percebidos nos currículos atuais, nos livros didáticos e em 
avaliações em larga escala. São evidências de uma compreensão específica de cidadania que, embora subsistente, passou a ser ressignificada por ocasião da reabertura política e do fim da Ditadura Militar no Brasil. A partir da década de 1980, a categoria cidadania passou a incorporar uma dimensão crítica (COELHO; COELHO, 2014, p. 359) que implica não somente na conscientização do indivíduo, mas em sua capacidade de ação visando ao aperfeiçoamento de sua cidadania. Como deixam claros os Parâmetros Curriculares Nacionais para o Ensino Médio,

\begin{abstract}
Nesta área (Ciências Humanas), que engloba também a Filosofia, deve-se desenvolver a tradução do conhecimento das Ciências Humanas em consciências críticas e criativas, capazes de gerar respostas adequadas a problemas atuais e a situações novas. Dentre estes, destacam-se a extensão da cidadania, que implica o conhecimento, o uso e a produção histórica dos direitos e deveres do cidadão e o desenvolvimento da consciência cívica e social, que implica a consideração do outro em cada decisão e atitude de natureza pública ou particular (BRASIL, 2000a, p. 21).
\end{abstract}

Um dos fatores apontados na literatura especializada para o reconhecimento do necessário desenvolvimento dessa consciência cívica é a "pressão mundial de descaracterização da soberania das nações periféricas" (LIBÂNEO; OLIVEIRA; TOSCHI, 2005, p. 118), a qual resulta da intensificação do processo de globalização. Ao mesmo tempo, porém, busca-se a inserção dos estudantes na comunidade global por meio da escolarização. A cidadania, nessa perspectiva, caracteriza-se não apenas pela conscientização ou sensibilização dos indivíduos para a importância e a singularidade dos laços culturais que os tornam membros da sociedade, mas pela capacidade "de interferir criticamente na realidade para transformá-la", no engajamento "na luta pela justiça social" e "na mudança da realidade em que vivem e no processo de desenvolvimento nacional" (LIBÂNEO; OLIVEIRA; TOSCHI, 2005, p. 119). Existe uma orientação para ação, para tomada de atitudes não voluntariosas, mas embasadas na formação específica ofertada nesse nível de ensino.

É em razão dessas orientações que se entende que a formação ofertada no Ensino Médio, ao acionar a categoria cidadania, também aponta 
para a implementação de um projeto societário democrático. O principal marco legal deflagrador desse conjunto de afirmações, como se viu, encontra-se na Constituição de 1988, especificamente no artigo 205. O artigo seguinte, ao postular valores como a igualdade de acesso à escola, a liberdade, o pluralismo no processo de aprendizado e a gestão democrática do ensino (BRASIL, 2017a, Art. 206), tem o efeito de esclarecer os sentidos que essa cidadania congrega. A produção normativa que segue à Constituição de 1988 incorpora e materializa essas afirmações. A Lei de Diretrizes e Bases da Educação Nacional (Lei no 9.394/1996), por exemplo, ao regulamentar os preceitos constitucionais educacionais reitera o papel específico da escola na formação dos indivíduos. Em seu artigo $22^{\circ}$ é estabelecida como finalidade principal do ensino básico o "desenvolvimento do educando", por meio de "uma formação comum capaz de assegurar o exercício da cidadania" (BRASIL, 2017b, Art. 22). A mesma afirmação, também presente no artigo $2^{\circ}$, é detalhada no artigo $35^{\circ}$ que trata especificamente do Ensino Médio (BRASIL, 2017b, Art. 35).

O perfil de saída dos educandos configurado nestes termos define um tipo de formação que dote os indivíduos de autonomia cognitiva e intelectual, habilitando-os a viver plenamente a sua condição de sujeitos históricos. Não se trata, como se vê, de uma formação a serviço de um projeto identitário puramente individualista. Uma educação nesse sentido não consiste meramente em um serviço, nem a formação é apenas um produto ofertado nas instituições escolares. Como se pode perceber no trecho a seguir, extraído do Parecer CNE/CEB no 5/2011, que trata das DCN para o Ensino Médio, essa formação consiste em um direito social consolidado nas democracias modernas cujo sentido é a vida em comunidade.

Concebida como forma de socializar as pessoas de acordo com valores e padrões culturais e ético-morais da sociedade e como meio de difundir de forma sistemática os conhecimentos científicos construídos pela humanidade, a 
educação escolar [e a formação que ela oferece] reflete um direito e representa componente necessário para o exercício da cidadania e para as práticas sociais. (BRASIL, 2011, p. 6)

Entendimento semelhante é encontrado nos Parâmetros Curriculares Nacionais para o Ensino Médio (PCNEM). De acordo com este documento, uma das funções dessa etapa é "a formação da pessoa, de maneira a desenvolver valores e competências necessários à integração de seu projeto individual ao projeto da sociedade em que se situa" (BRASIL, 2000a, p. 10). A formação, nesse sentido, possui duas dimensões indissociáveis: uma individual, para a cidadania; e outra societal, para a democracia. Do ponto de vista da produção dos saberes escolares no interior das disciplinas que compõem o currículo e a formação, o reconhecimento dessa inter-relação entre formação escolar e projeto de sociedade é demais consequente. 0 projeto societário democrático definido na Constituição fornece um conjunto de valores que repercute diretamente sobre o currículo, redimensionando e reconfigurando a conformação dos saberes escolares. Conforme aponta o parecer CNE/CEB no 5/2011,

[...] a educação escolar deve fundamentar-se na ética e nos valores da liberdade, justiça social, pluralidade, solidariedade e sustentabilidade, cuja finalidade é o pleno desenvolvimento de seus sujeitos, nas dimensões individual e social de cidadãos conscientes de seus direitos e deveres, compromissados com a transformação social. (BRASIL, 2011, p. 9)

Como se vê nesta citação das DCN e na anterior, extraída dos PCN, a Legislação Educacional reconhece certos valores e atitudes como componentes curriculares que devem orientar a produção dos saberes escolares. É importante enfatizar isto. O aspecto valorativo não somente é reconhecido no ordenamento jurídico educacional, como também antecede e vincula o aspecto instrucional relativo ao saber de referência específico de cada disciplina. De acordo com as DCN Gerais para a Educação Básica,

O currículo deve difundir os valores fundamentais do interesse social, dos direitos e deveres dos cidadãos, do respeito ao bem comum e à ordem democrática, 
considerando as condições de escolaridade dos estudantes em cada estabelecimento, a orientação para o trabalho, a promoção de práticas educativas formais e não-formais (BRASIL, 2010b, Art. 13, Parágrafo 10).

Não se trata, porém, como se pode comprovar acima, de quaisquer valores, mas daqueles que interessam à sociedade, especificamente o respeito à diversidade, à diferença e ao acordo social comum que se materializa no Direito, isto é, na própria Legislação. Ao assumir que estes "valores fundamentais do interesse social" (BRASIL, 2010b, Art. 13, Parágrafo $1^{\circ}$ ) devem ser difundidos por meio do currículo, a Legislação Educacional está reconhecendo-os como parâmetros para a conformação dos saberes escolares. O reconhecimento legal destes valores, contudo, não é realizado somente em função do que prescrevem as DCN Gerais para a Educação Básica. Os mesmos princípios são reafirmados em outros documentos, como as DCN para as relações étnico-raciais (BRASIL, 2004a, p. 1) e, antes, pelas primeiras DCN para o Ensino Médio (BRASIL, 1998b, Art. 30, Inciso II). O ordenamento jurídico educacional vigente para o ensino médio, como um todo, é constituído por afirmações explicitamente ideológicas que, é importante ressaltar, vão de encontro à retórica conservadora que defende uma educação "neutra" ou livre de ideologias. Não se trata, porém, de uma simples abertura jurídica para os professores em seu metier, mas de uma vinculação, uma exigência de que a formação educacional contemple e alcance essas "ideologias".

Essas demandas, todavia, não são aleatórias ou casuais. 0 estabelecimento desses valores reflete um conjunto de preocupações que se materializaram primeiramente na Constituição de 1988 (BURGOS, 2014, p. 16) quando, já em seu preâmbulo, declara a instituição de um Estado Democrático de Direito, destinado a assegurar o exercício dos direitos sociais e individuais, a liberdade, a segurança, o bem-estar, o desenvolvimento, a igualdade e a justiça como valores de uma sociedade fraterna e sem preconceitos (BRASIL, 2017a, preâmbulo). Trata-se de um 
projeto de sociedade que disciplina todos os aspectos da vida em comunidade, repercutindo, inclusive, sobre a formação a ser ofertada pela escola. Na verdade, em função dessas preocupações, a educação formal passa a estar no centro da afirmação desse projeto de sociedade na medida em que a consecução dele passa pela formação que a escola oferece.

A Constituição, isto posto, é o marco deflagrador da normatização da formação com base nestes valores. É ela também que, considerando-se seu contexto de produção, consubstancia o entendimento dos sentidos dos princípios por ela assumidos e sistematicamente reafirmados nos documentos que compõem a Legislação Educacional que a sucede. É importante atentar para isto. As afirmações destacadas da documentação no decorrer da análise realizada não se conformam de maneira aleatória, descoladas do contexto histórico-social formado pelos sujeitos e instituições que demandaram em sua elaboração. No que tange ao reconhecimento legal de certos valores como parâmetros para conformação dos saberes escolares, o contexto do qual emanou a Constituição de 1988 não deixa dúvidas de que a coerência de suas afirmações se encontra nas demandas sociopolíticas oriundas do processo de redemocratização, ocorrido durante a década de 1980. Àquele momento, a formação para a democracia se configurava como um mecanismo de defesa da sociedade contra as ameaças aos direitos tidos como fundamentais ao exercício da cidadania. 0 Estado de exceção em que mergulhou o país entre 1964 e 1985 serviu de base para a conformação de um discurso que passou a informar, a partir de então, não somente as práticas sociais em geral, mas, em particular, as práticas educacionais. Segundo Marcelo Baumann Burgos,

[...] a escola passou a estar no centro do projeto civilizacional brasileiro. Ou, mais especificamente, no centro do projeto de afirmação da construção da democracia entre nós. Ainda que não seja nova, remetendo à mobilização dos "pioneiros da educação" nos anos 1920, é somente a partir de 1988 que a educação realizada pela escola pública é reconhecida como central ao projeto de afirmação de uma cultura democrática" (BURGOS, 2014, p. 14). 
Para Burgos, a Constituição de 1988 foi a síntese de um diagnóstico amadurecido ao longo dos anos 1970 e 1980. Esta síntese apontava para a necessidade de construir uma ordem constitucional capaz de pôr fim ao autoritarismo (BURGOS, 2014, p. 14). Foi, portanto, em função da oposição a uma realidade marcada pelo arbítrio e pela ilegalidade que se forjou 0 discurso democrático assumido como referência para o tipo de formação a ser ofertado pela escola.

A formação para a democracia era, àquele momento, a demanda mais relevante para uma sociedade que estava saindo de um regime marcado pelo arbítrio e a ilegalidade. Foi em função disso que, desde a Constituição Federal até as diretrizes mais recentes, têm-se reafirmado o papel da escola na oferta dessa formação específica.

A assunção de certos valores como objetivo da educação formal reflete essa preocupação com o estabelecimento do projeto societal democrático idealizado, o qual possui implicações sobre prática educacional (CURY; HORTA; FÁVERO, 2014, p. 30) e a conformação dos saberes escolares. Uma das implicações é a compreensão do processo formativo como um trabalho educacional e não simplesmente instrucional, como o que reivindicam os voluntaristas conservadores. No atual contexto da Legislação educacional vigente para o ensino médio, não há abertura legal para a construção de saberes escolares pautados exclusivamente nos saberes acadêmicos específicos que servem de referência às disciplinas. Isso quer dizer que a História escolar, por exemplo, não pode estar baseada apenas nas leituras historiográficas resultantes de pesquisas sobre o passado, nas teorias e/ou filosofias da História. Não há espaço nem mesmo para a precedência desse conhecimento na conformação dos saberes escolares. Evidentemente, não há como dissociar a dimensão educativa da dimensão instrucional. Contudo, em termos analíticos, verifica-se pela primeira vez a assunção e a precedência destes valores específicos ligados às categorias cidadania e democracia no escopo da Legislação Educacional. 
O reconhecimento da inter-relação entre a formação a ser oferecida pelas escolas e os valores ligados às categorias cidadania e democracia implica também na reconfiguração dos procedimentos envolvidos na produção dos saberes escolares. $O$ aspecto mais preliminar dessa reconfiguração é a consideração de um horizonte externo às disciplinas, qual seja o horizonte dos valores assumidos. Segundo o artigo $27^{\circ}$ da LDB, a produção dos conteúdos curriculares deve ser pautada pela "difusão de valores fundamentais ao interesse social, aos direitos e deveres dos cidadãos, de respeito ao bem comum e à ordem democrática" (BRASIL, 2017b, Art. 27, Inciso I). Impõe-se um critério moral de legitimação e organização a partir do qual os demais saberes deverão ser acionados.

Essa nova configuração epistemológica, importa destacar, vai de encontro à representação tradicional de saber escolar constituída a partir da influência do paradigma da racionalidade técnica, segundo a qual o saber de referência específico de cada disciplina constitui a fonte preponderante e até exclusivista da produção deste saber. A legitimidade do saber escolar não se estabelece mais apenas em função de seu espelho acadêmico, mas, do ponto de vista legal, a partir dos valores constituintes do projeto societal democrático conformado no escopo do processo de redemocratização, ocorrido durante a década de 1980.

Outra implicação epistemológica da assunção dos valores ligados às categorias cidadania e democracia diz respeito à noção de conteúdo que é trabalhado nas disciplinas. Ela é modificada e alargada, não se restringindo apenas a seç̧ões dos saberes acadêmicos específicos que servem de referência às disciplinas. Passa a englobar novas temáticas e os próprios valores significantes da cidadania e da democracia. Isso muda a maneira como o trabalho docente é desenvolvido. A título de exemplo, uma aula de História para o $1^{\circ}$ ano do ensino médio, nessa perspectiva, deixa de ser simplesmente sobre Atenas e passa a ser sobre a cidadania na Antiguidade Clássica ou sobre diferentes formas de funcionamento do governo, podendo englobar a democracia e/ou diferentes formas de governo e princípios de deliberação. 
Tendo em vista que não se pode formar para a democracia e a cidadania em um contexto escolar autoritário, excessivamente burocratizado e fechado à participação, verifica-se também a necessária reformulação dos procedimentos envolvidos na conformação dos saberes escolares. Tanto professores quanto alunos precisam ter uma nova postura diante dos saberes construídos no espaço escolar. Nem os professores devem ser vistos como a fonte única do saber, nem os alunos como agentes passivos receptores desse saber. Para cumprir esse ideal a escola precisa abrir-se à participação dos sujeitos que a compõem. Professores e alunos precisam ter parte no processo de produção dos saberes escolares e, indo além, nas deliberações que a eles dizem respeito.

\section{Considerações Finais}

As afirmações legais que discriminam a formação ofertada pelas escolas não constituem um discurso retórico e aleatório feito pelos legisladores. Os significados que as categorias cidadania e democracia assumem no escopo da Legislação educacional para o Ensino Médio estabelecem uma série de parâmetros para a produção dos saberes escolares, na medida em que caracterizam essa formação tanto em um sentido individual quanto em um sentido social.

O sentido individual, como se viu, é apontado desde a Constituição Federal. De acordo com o artigo 205 deste documento, o processo educacional deve dotar os indivíduos de autonomia cognitiva e intelectual, habilitando-os a viver plenamente a condição de sujeitos históricos. A formação nesse sentido é para o exercício da cidadania. O segundo sentido é caracterizado a partir da LDB que, ao especificar como essa meta constitucional deverá ser alcançada, estabelece que a formação deve ser pautada nos valores desejados para a vida em sociedade, deve estar voltada "à divulgação de valores fundamentais ao interesse social e à 
preservação da ordem democrática" (BRASIL, 2011, p. 45), "deve difundir os valores fundamentais do interesse social, dos direitos e deveres dos cidadãos, do respeito ao bem comum e à ordem democrática" (BRASIL, 2010a, p. 22; BRASIL, 2010b, Art. 13, Parágrafo 10; BRASIL, 2017b, Art. 27, Inciso I).

Conforme as DCN Gerais para a Educação Básica, um dos documentos que retomam e consubstanciam essas afirmações, trata-se especificamente do respeito à diversidade, à diferença e ao acordo social comum que se materializa no Direito. Uma das implicações da assunção destes valores como parâmetros legais para a conformação dos saberes escolares é a hierarquização promovida entre os aspectos educacional e instrucional desses saberes. Os diversos saberes que são articulados por ocasião da produção dos saberes escolares no interior das disciplinas devem ser sintetizados em função da democracia e do exercício da cidadania. Esse entendimento vai de encontro à representação tradicional de saber escolar baseada nos pressupostos da racionalidade técnica, atuando de maneira específica sobre os saberes acadêmicos específicos que servem de referência às disciplinas. Estes saberes são reconfigurados e redimensionados, não sendo mais nem a única, nem a principal referência para as disciplinas. Exige-se que os mesmos sejam produzidos considerando-se um parâmetro que lhes é externo, uma finalidade que se consubstancia no trato dos valores legislados, cuja coerência não é apenas política ou jurídica, mas social, porque está relacionada às demandas que emergiram durante o processo de redemocratização, na década de 1980.

A Escola e o saber nela construído e praticado, isto posto, estão em íntima relação com as expectativas da sociedade que a mantém e informa sobre a Educação. É por isso que esta não se conforma como uma tradução de saberes acadêmicos em conteúdos escolares. A Educação, assim entendida, compreende saberes diversos, apropriados e reordenados pela Escola, mas em função dos propósitos da sociedade. Resulta desta formulação a premissa de que as reformas curriculares, quaisquer que sejam elas, não podem prescindir de amplo debate, envolvendo diversos setores da sociedade. Resulta desta formulação, ainda, que os saberes 
escolares são restringidos pela mesma sociedade, de modo que todos aqueles que concorrem para a sua concretização devem ter isso em conta a começar por aqueles que constituem os currículos escolares, atribuindoIhes sentido em função dos propósitos estabelecidos pela sociedade e expressos na Legislação, sem esquecer dos que participam dos processos de formação docente, dimensionando o saber de referência em função da Escola.

\section{Referências}

BRASIL. Ministério da Educação. Conselho Nacional de Educação. Parecer CNE/CEB $n^{\circ} 15$, de $1^{\circ}$ de junho de 1998. Diretrizes Curriculares Nacionais para o ensino Médio. Brasília: MEC, 1998a. Disponível em:

http://portal.mec.gov.br/cne/arquivos/pdf/1998/pceb015_98.pdf. Acesso em 22 mar. 2018.

BRASIL. Ministério da Educação. Conselho Nacional de Educação. Resolução CNE/CEB no 3, de 26 de junho de 1998. Diretrizes Curriculares Nacionais para o ensino Médio. Brasília: MEC, 1998b. Disponível em:

http://portal.mec.gov.br/cne/arquivos/pdf/rceb03_98.pdf. Acesso em: 22 mar. 2018

BRASIL. Ministério da Educação. Parâmetros Curriculares Nacionais, ensino médio: bases legais. Brasília: Ministério da Educação, 2000a. v. 1.

Disponível em: http://portal.mec.gov.br/seb/arquivos/pdf/blegais.pdf.

Acesso em: 22 mar. 2018.

BRASIL. Ministério da Educação. Parâmetros Curriculares Nacionais, ensino médio: linguagens, códigos e suas tecnologias. Brasília: Ministério da Educação, 2000b. v. 2. Disponível em:

http://portal.mec.gov.br/seb/arquivos/pdf/14_24.pdf. Acesso em: 22 mar. 2018.

BRASIL. Ministério da Educação. Parâmetros Curriculares Nacionais, ensino médio: ciências da natureza, matemática e suas tecnologias. Brasília: Ministério da Educação, 2000c. v. 3. Disponível em: http://portal.mec.gov.br/seb/arquivos/pdf/ciencian.pdf. Acesso em: 22 mar. 2018.

BRASIL. Ministério da Educação. Parâmetros Curriculares Nacionais, ensino médio: ciências humanas e suas tecnologias. Brasília: Ministério da 
Educação, 2000d. v.4. Disponível em:

http://portal.mec.gov.br/seb/arquivos/pdf/cienciah.pdf. Acesso em: 22 mar. 2018.

BRASIL. Ministério da Educação. $P C N+$ Ensino Médio: orientações educacionais complementares aos Parâmetros Curriculares Nacionais: ciências humanas e suas tecnologias. Brasília: MEC: SEMTEC, 2002a. Disponível em:

http://portal.mec.gov.br/seb/arquivos/pdf/CienciasHumanas.pdf. Acesso:

22 mar. 2018.

BRASIL. Ministério da Educação. PCN+ Ensino Médio: orientações educacionais complementares aos parâmetros curriculares nacionais. linguagens, códigos e suas tecnologias. Brasília: MEC: SEMTEC, 2002b. Disponível em:

http://portal.mec.gov.br/seb/arquivos/pdf/linguagens02.pdf. Acesso em: 22 mar. 2018.

BRASIL. Ministério da Educação. PCN+ Ensino Médio: orientações educacionais complementares aos Parâmetros Curriculares Nacionais: ciências da natureza, matemática e suas tecnologias. Brasília: MEC: SEMTEC, 2002c. Disponível em:

http://portal.mec.gov.br/seb/arquivos/pdf/CienciasNatureza.pdf. Acesso em: 22 mar. 2018.

BRASIL. Ministério da Educação. Conselho Nacional de Educação. Parecer CNE/CP no 3, de 10 de março de 2004. Diretrizes Curriculares Nacionais para a Educação das Relações Étnico-Raciais e para o Ensino de História e Cultura Afro-Brasileira e Africana. Brasília: MEC, 2004a. Disponível em: http://portal.mec.gov.br/dmdocuments/cnecp_003.pdf. Acesso em: 22 mar. 2018.

BRASIL. Ministério da Educação. Conselho Nacional de Educação. Resolução CNE/CP no 1, de 17 de junho de 2004. Institui Diretrizes Curriculares Nacionais para a Educação das Relações Étnico-Raciais e para o Ensino de História e Cultura Afro-Brasileira e Africana. Diário Oficial da União: seção 1, Brasília, p. 11, 22 jun. 2004b. Disponível em:

http://portal.mec.gov.br/cne/arquivos/pdf/res012004.pdf. Acesso em: 22 mar. 2004.

BRASIL. Ministério da Educação. Orientações Curriculares para o Ensino Médio: linguagens, códigos e suas tecnologias. Brasília: MEC: SEB, 2006a. v.1. Disponível em:

http://portal.mec.gov.br/seb/arquivos/pdf/book_volume_01_internet.pdf. Acesso em: 22 mar. 2018.

BRASIL. Ministério da Educação. Orientações Curriculares para o Ensino Médio: ciências da natureza, matemática e suas tecnologias. Brasília: MEC: SEB, 2006b. v. 2. Disponível em: 
http://portal.mec.gov.br/seb/arquivos/pdf/book_volume_02_internet.pdf. Acesso em: 22 mar. 2018.

BRASIL. Ministério da Educação. Orientações Curriculares para o Ensino Médio: ciências humanas e suas tecnologias. Brasília: MEC: SEB, 2006c. v. 3. Disponível em:

http://portal.mec.gov.br/seb/arquivos/pdf/book_volume_03_internet.pdf. Acesso em: 22 mar. 2018.

BRASIL. Ministério da Educação. Conselho Nacional de Educação.. Parecer CNE/CEB n० 7, de 07 de abril de 2010. Diretrizes Curriculares Nacionais Gerais para a Educação Básica. Diário Oficial da União: seção 1, Brasília, p. 10, 9 jul. 2010a. Disponível em:

http://portal.mec.gov.br/index.php?option=com_docman\&view=download\& alias=5367-pceb007-10\&Itemid=30192. Acesso em: 22 mar. 2018.

BRASIL. Ministério da Educação. Conselho Nacional de Educação. Resolução CNE/CEB no 4, de 13 de julho de 2010. Define Diretrizes Curriculares Nacionais Gerais para a Educação Básica. Diário Oficial da União: seção 1, Brasília, p. 824, 14 jul. 2010b. Disponível em:

http://portal.mec.gov.br/dmdocuments/rceb004_10.pdf. Acesso em: 22 mar. 2018.

BRASIL. Ministério da Educação. Conselho Nacional de Educação. Parecer CNE/CEB n० 5, de 04 de maio de 2011. Diretrizes Curriculares Nacionais para o Ensino Médio. Diário Oficial da União: seção 1, Brasília, p. 10, 24 jan. 2011. Disponível em:

http://portal.mec.gov.br/index.php?option=com_docman\&view=download\& alias $=9915$-pceb005-11-1-1\&category_slug=fevereiro-2012-

pdf\&Itemid=30192. Acesso em: 22 mar. 2018.

BRASIL. Ministério da Educação. Conselho Nacional de Educação. Resolução CNE/CEB no 2, de 30 de janeiro de 2012. Define Diretrizes Curriculares Nacionais para o Ensino Médio. Diário Oficial da União: seção 1, Brasília, p. 20, 31 de jan. 2012. Disponível em:

http://portal.mec.gov.br/index.php?option=com_docman\&view=download\& alias=9917-rceb002-12-1\&Itemid=30192. Acesso em: 22 mar. 2018.

BRASIL. [Constituição (1988)]. Constituição da República Federativa do Brasil. Texto constitucional promulgado em 05 de outubro de 1988, com as alterações adotadas pelas emendas constitucionais nos 1/1992 a 96/1997, pelo decreto legislativo no 186/2008 e pelas Emendas constitucionais de revisão nos 1 a 6/1994. 52. Brasília: Câmara dos Deputados: Edições Câmara, 2017a. Recurso eletrônico. 
BRASIL. [Lei Darcy Ribeiro (1996)]. LDB: lei de diretrizes e bases da educação nacional: lei no 9.394, de 20 de dezembro de 1996, que estabelece as diretrizes e bases da educação nacional. 14. ed. Brasília: Edições Câmara. 2017b. Recurso eletrônico.

BRASIL. Presidência da República. Lei no 13.415, de 16 de fevereiro de 2017. Altera as Leis n 0 9.394, de 20 de dezembro de 1996, que estabelece as diretrizes e bases da educação nacional, e 11.494, de 20 de junho 2007, que regulamenta o Fundo de Manutenção e Desenvolvimento da Educação Básica e de Valorização dos Profissionais da Educação, a Consolidação das Leis do Trabalho - CLT, aprovada pelo Decreto-Lei no 5.452, de $1^{\circ}$ de maio de 1943, e o Decreto-Lei no 236, de 28 de fevereiro de 1967; revoga a Lei no 11.161, de 5 de agosto de 2005; e institui a Política de Fomento à Implementação de Escolas de Ensino Médio em Tempo Integral. Brasília: Presidência da República, 2017c. Disponível em:

http://www.planalto.gov.br/ccivil_03/_ato2015-2018/2017/lei//13415.htm. Acesso em: 22 mar. 2018.

BLOOM, Benjamin S. Inocência em educação. Cadernos de Pesquisa, Uberlândia, n.16, p.63-71, 2013.

BURGOS, Marcelo Baumann. Educação, Sociedade e democracia: a transição democrática da escola. In: D'ARAUJO, Maria Celina (ed.). Redemocratização e mudança social no Brasil. Rio de Janeiro: Editora FGV, 2014. p.14-39. Recurso eletrônico.

CAIMI, Flávia Eloisa. Por que os alunos (não) aprendem História? reflexões sobre ensino, aprendizagem e formação de professores de história. Tempo, Rio de Janeiro, v. 11, n. 21, p. 27-42, 2006.

CÂMARA DOS DEPUTADOS. Projeto de Lei no 6.840, de 27 de novembro de 2013. Altera a Lei no 9.394, de 20 de dezembro de 1996, que estabelece as diretrizes e bases da educação nacional, para instituir a jornada em tempo integral no ensino médio, dispor sobre a organização dos currículos do ensino médio em áreas do conhecimento e dá outras providências. Brasília: Câmara dos Deputados, 2013. Disponível em:

http://www.camara.gov.br/sileg/integras/1295592.pdf. Acesso em: 22 mar. 2018.

CASTRO, Maria Helena Guimarães; TORRES, Haroldo da Gama; FRANÇA, Danilo França. Os jovens e o gargalo do ensino médio brasileiro. $1^{a}$ Análise Seade, São Paulo, v. 5, n. 4, p. 1-30, ago. 2013.

CERRI, Luis Fernando. Saberes históricos diante da avaliação do ensino: notas sobre os conteúdos de história nas provas do Exame Nacional do Ensino Médio-ENEM. Revista Brasileira de História, v.24, n.48, p.213-231, 2004. 
CHERVEL, André. História das disciplinas escolares: reflexões sobre um campo de pesquisa. Teoria \& educação, Porto Alegre, v. 2, p. 177-229, 1990.

COELHO, Mauro Cezar; COELHO, Wilma de Nazaré Baía. História, historiografia e saber histórico escolar: a educação para as relações étnicoraciais e o saber histórico na literatura didática. Revista Espaço Pedagógico, Passo Fundo, v. 21, n. 2, p. 358-379, 2014.

CURY, Carlos Roberto Jamil; HORTA, José Silvério Baía; FÁVERO, Osmar. A relação educação-sociedade-estado pela mediação jurídico-constitucional. In: FÁVERO, Osmar. (ed.). A educação nas constituintes brasileiras: 18231988. Campinas: Autores Associados, 2014. p. 4-33.

FINI, Maria Inês. Currículo e avaliação: uma articulação necessária à aprendizagem. In: NEGRI, B.; TORRES, H. G.; CASTRO, M. H. G (ed.). Educação básica no estado de São Paulo: avanços e desafios. São Paulo: Fundação SEADE/FDE, 2014. p.359-388.

FRIGOTTO, Gaudêncio; CIAVATTA, Maria. Perspectivas sociais e políticas da formação de nível médio: avanços e entraves nas suas modalidades. Educação \& Sociedade, Campinas, v. 32, p. 619-638, 2011.

GATTI JUNIOR, Décio. A pedagogia tecnicista no contexto educacional brasileiro do golpe militar de 1964: o projeto educacional do Instituto de pesquisas e estudos sociais (1961-1972). Cadernos de História da Educação, Uberlândia, v. 9, n.1 p.45-63, jan./jun. 2010.

KNAUSS, Paulo. O desafio da ciência: modelos científicos no ensino de história. Cadernos Cedes, Campinas, v. 25, n. 67, p. 279-295, 2005.

LAVILLE, Christian. A guerra das narrativas: debates e ilusões em torno do ensino de História. Revista Brasileira de História, São Paulo, v. 19, n. 38, p. 125-138, 1999.

LIBÂNEO, José Carlos; OLIVEIRA, João Ferreira; TOSCHI, Mirza Seabra. Educação escolar: política, estrutura e organização. São Paulo: Editora Cortez, 2005. 544 p.

MONTEIRO, Ana Maria. A história ensinada: algumas configurações do saber escolar. História \& Ensino, Londrina, v. 9, p. 9-35, 2003.

MONTEIRO, Ana Maria. Professores de história: entre saberes e práticas. Rio de Janeiro: Editora Mauad X, 2007. 249 p. 
MOREIRA, Antônio Flávio Barbosa. Currículo, utopia e pós-modernidade. In: MOREIRA, Antônio Flávio Barbosa (ed.). Currículo: questões atuais.

Campinas: Papirus, 1997. p. 9-28.

SANTOMÉ, Jurjo Torres. As culturas negadas e silenciadas no currículo. In: SILVA, Tomaz Tadeu da. Alienígenas na sala de aula. Petrópolis: Vozes, 1995. p.159-177.

SALDANHA, Rafael da Silva. O discurso legal sobre a conformação dos saberes escolares no Ensino Médio. Dissertação (Mestrado) - Programa de Pós-graduação em Currículo e Gestão da Escola Básica (PPGED, Instituto de Ciências da Educação, Universidade Federal do Pará, Belém, 2017.

SILVA, Tomaz Tadeu. Documentos de identidade: uma introdução às teorias do currículo. 2. ed. Belo Horizonte: Editora Autêntica, 1999.

SOUZA NETO, Alaim. Práticas e saberes docentes em estágios curriculares. Revista Educação e Cultura Contemporânea, Rio de Janeiro, v.16, n. 44, p.394-413, 2019.

NUNES, César. Quando a casa vira escola: a modernidade pedagógica no Brasil. In: MONTEIRO, A. M.; GASPARELLO, A. M.; MAGALHÃES, M. D. (ed.). Ensino de história: sujeitos, saberes, práticas. Rio de Janeiro: Editora Mauad X: Faperj, 2007. p. 32-49. 